\title{
CORRESPONDENCE.
}

\section{A FEW LAST WORDS ON GRADUATION.}

To the Editor of the Jowrnal of the Institute of Actuaries.

Srn,-Mr. Sprague has conclusively proved both his propositions, which, I think, may be shortly stated as follows, namely:

First-A formula calculated to third differences will not give fourth differences correctly.

Second-An arithmetical graduation is not suited to a geometrical series.

The formulas which you have done me the honour to publish were stated in distinct terms to be arithmetical graduations correct to third differences only. It has not been claimed for them that they are applicable to every order of differences and to every conceivable series.

The extent to which formulas of the kind "distort the facts", \&c., in graduating a table of mortality, has been shown by $\mathrm{Mr}$. Woolhouse (Journal xv, 396).

Anyone who is satisfied with the measure of accuracy attained when the formulas are used for the purpose for which they were furnished, will find in them a ready means of testing what a graphist has been doing - whether he has* "faithelly reproduced every well pronounced characteristic in the original"; or whether he has applied his method with the conrage of a railway manager who, desiring to represent his line as more direct than another, draws a curve differing little from a straight line, and groups his facts so as to bring every important town in the neighbourhood upon that curve.

My belief that Mr. Sprague himself will always employ the graphic method with skill and fidelity has been expressed in a previous communication. It is, however, only fair to notice that, with my untouched results before him, he has been able to rectify and beautify his own to any extent necessary for claiming superiority; and that, supposing this attained in the latter case, it is possible that similar labour bestowed upon the former might produce something better still.

$$
\text { I am, Sir, }
$$

Your obedient servant,

February 1887 .

J. A. HIGHAM.

* Mr. Peter Gray's introduction to the Institute Tables (p. ix). 